\title{
Sustainable Communications and Innovation: Different Types of Effects from Collaborative Research Including University and Companies in the ICT-Sector
}

\author{
Mattias Höjer ${ }^{1}$, Katarina Larsen ${ }^{2}$, and Helene Wintzell ${ }^{3}$ \\ ${ }^{1}$ Centre for Sustainable Communications, Royal Institute of Technology, Stockholm, Sweden \\ hojer@kth.se \\ ${ }^{2}$ Div. History of Science, Technology and Environment, \\ Royal Institute of Technology, Stockholm, Sweden \\ katarina. larsen@abe.kth.se \\ ${ }^{3}$ Helene Wintzell AB, Stockholm, Sweden \\ helene@helenewintzell.se
}

\begin{abstract}
This paper presents experiences from the Centre for Sustainable Communications (CESC) located at KTH - The Royal Institute of Technology in Stockholm. Since 2007, the centre has carried out research in collaboration with private firms in the information and communication technology (ICT) and media sectors as well as with public sector organizations in the city of Stockholm. The aim is to share experiences from how the partners of the centre describe benefits and effects from collaborative research. Since the centre is focusing on use of ICT and media technology, rather than technology development per se, this provides an account of a wide range of effects from universityindustry collaborations and new insights into the innovation processes targeting sustainability in the ICT and media sectors. This is an important perspective of sustainable and responsible innovation that is not captured in traditional innovation surveys (counting the number of new products or patents). Areas examined here include: increased knowledge and competence, new contacts and networks, publications, methods and new technology as well as changes in business operations and behaviour targeting sustainable solutions. The results also confirm firm-level business value as a driver for sustainability and provide experiences from involving users in the quest for sustainable and responsible innovation.
\end{abstract}

Keywords: added value, benefit, collaboration, effects, environment, ICT.

\section{Sustainable Communications: Collaboration with Public and Private}

The Centre for Sustainable Communications (CESC) was established in 2007 as one of 18 so-called Vinnova Centres of Excellence in Sweden. Centres within the Vinnova Excellence Centre programme receive core funding from the Swedish Governmental Agency for Innovation Systems (Vinnova) complemented with contributions from the Universities and a group of partners. The programme aim is “... to create 
and develop vigorous academic research milieus in which industrial and/or public partners actively participate in order to derive long-term benefits for society. The programme is also a link in the governmental effort to develop university-industry interaction." [14]. The objective of the Vinnova Excellence Centre programme is to promote sustainable growth in Sweden. This is expected to happen through concentrating experts from different fields in interdisciplinary research centres, and developing products, processes and services [14].

It can be noted that the "long-term benefit for the society" that is mentioned as the aim of the programme is translated into a "development of products, processes and services" in the formulation of the objective. This slight change of words is interesting for centres working towards societal benefits, but not necessarily directly linked to products, processes and services, like CESC. Can societal benefits always be measured in products, processes and services? Is this always what industrial partners in university-industry partnerships demand?

This leads to a bigger question about the usefulness of university-based research, the third mission of universities and, more specifically, research and innovation processes that lead to other types of results than development of new technology or products that are close to market.

The excellence centres, such as CESC, that have been established have to find forms of interaction that will enable collaborative projects to address some of these major challenges ahead and create added value for both industry and academia. The user perspective is important in this work in order to face the challenges of new needs defined by different types of user groups, as well as for private actors' needs, so as to catalyse new innovation processes and create new products.

The areas of activity for CESC include information and communication technology (ICT), media and sustainable development where focus of the areas of activity is environmental issues linked to ICT and media, but also social effects. The research is carried out in collaboration between researchers based at the Royal Institute of Technology (KTH), private firms and regional authorities. This includes collaborative research with people from larger telecommunication firms (such as Ericsson and TeliaSonera), from the City of Stockholm and Stockholm county, as well as major organizations from the media sector (such as Bonnier, Stampen, SVT - Swedish public service TV, and the Swedish media publishers association).

Taking the objective of development of products, processes and services into consideration, it is likely that many partners join Vinnova Excellence centres with an ambition of getting rather direct benefits for business. With a centre like CESC focusing on environmental research, the link may not be as direct and, therefore, the partners might have other reasons for joining. Instead, they may be in the collaborative research venture in order to increase the understanding of ICT's potential environmental impacts and to increase knowledge about how it can be analysed. In that case, the focus is to get a better understanding of environmental impacts of ICT - rather than focusing on development of new short-term businesses and technology. This would go hand in hand with the fact that innovation processes aiming for more sustainable solutions naturally are informed by an increased understanding of environmental impacts and how these can be analysed to capture barriers for introducing 
more sustainable solutions as well as understanding behavioural change when new technology solutions are introduced. With this background, the management of CESC decided to examine how the partners looked upon benefits of being a part of CESC, and started an initiative in 2011 to analyse this.

The aim of this paper is to investigate what benefits partners see in industrysociety-university collaborations on environmental research, and how this relates to long-term benefits for society. The case used here is the VinnEx Centre for Sustainable Communications, CESC. We are using the CESC internal study on partner benefit from 2011 as our main empirical material.

\section{The Investigation of Effects from Collaboration with CESC}

In this paper we report on an examination of how the research partners engaged in collaborative research in CESC have expressed different dimensions of "usefulness" or "effects" from the joint research activities. The immediate outcomes of CESC may not be products, processes or services. This enables an examination of other dimensions of expected and perceived benefits from collaborative research.

There may be many reasons for research partners to collaborate with universities since there are many different domains of activity that they can refer to their own organization or their members. In order to find these reasons, CESC performed an interview study during 2011 with researchers in academia, and their collaborators in the private sector, about their views on different types of "usefulness" stemming from the collaborative projects at CESC.

One reason for raising these issues at CESC is the variety in the forms of collaboration that the centre has with different types of project partners including collaboration with larger companies in the traditional ICT industry, service companies (in media technology) and public sector organizations at the municipal and county level with an interest in developing new ICT solutions targeting more sustainable communication.

Partners are a crucial and indispensable part of any excellence centre, and there is an outspoken demand on excellence centres to create added-value and to be useful. The interview study at CESC in 2011 had several goals. They were to:

- Show what use and which results were the outcome of the collaboration.

- Describe how the collaboration is operating and suggest improvements.

- Describe partners' preferences on future activities.

The investigation was mainly undertaken through interviewing CESC participants, and using literature to analyse and interpret the interviews. The interview guide was developed during the period of interviews, and thus the responses are not directly comparable. It was an explicit aim of the study to get as much information from each interview as possible, and to do so by using experiences from previous interviews to improve the questionnaire. Moreover, in parallel with the interviews, some literature was used mainly as a help to navigate and structure the responses. When summarizing the results, a Canadian study [12] was important for structuring the results. This 
study, and other studies, were used when developing the interview guide, in order to find ways of identifying the partner benefits. Forty-four people were interviewed (see table 1), including representatives from virtually all partners. Most of the interviews were group interviews, so that several people from the same partner were interviewed at the same time. One of the authors of this paper (Wintzell) made all the interviews. She had deep knowledge regarding CESC and its partners, since she had been director of the centre 2008-2009 and is currently a member of the CESC board of managers. She continuously discussed the interviews with the other two authors of this paper. One of those authors (Höjer) is the current director of CESC, and the other is a researcher on innovation and environment.

Thus, the interview study should not be seen as an objective attempt to define the pros and cons of the partnership, but rather as a way of searching for reasons for the partners to take part in CESC. Each of them pays about 25,000 Euro per year and allocates 0.5-3 full-time employees to CESC activities. Since CESC does not produce so many direct products, processes and services, the rationale for the partnership must be another.

Table 1. Number of interviewees at each partner

\begin{tabular}{ll}
\hline Partner & Number of interviewees \\
\hline Bonnier & 4 \\
Ericsson & 7 \\
Community hub Foundation & 2 \\
Institute for Futures studies & 1 \\
Stockholm County Council & 2 \\
Stampen & 4 \\
City of Stockholm & 2 \\
SVT & 3 \\
TeliaSonera & 3 \\
Swedish Media Publishers Association & 3 \\
KTH Holding & 1 \\
KTH heads of units & 7 \\
KTH project leaders & 5 \\
Sum & 44 \\
\hline
\end{tabular}

\section{$3 \quad$ What Is Added Value and Usefulness?}

A set of categories of "added value" was developed as a framework for analysis based on a review of literature on university-industry collaboration [4], an analysis of effects from collaborative research and channels for knowledge transfers [3] and a study about measuring societal impacts from participatory sustainability research [12]. The study about channels of knowledge transfer was carried out in three areas of technology innovation and was designed to reveal the variety and broad scope of areas of 
interaction between university-based researchers and industry in the United Kingdom (UK). The wide range of activities originating from a great variety of research partners is also relevant to take into consideration when analysing the added value that partners see from participating in projects hosted by CESC.

In summary, there are two take-home messages from the study on channels for knowledge transfer. Firstly, that the private sector collaborates with academia to get access to networks (that they would not have access to otherwise) and skills relating to methods and problem formulations in an academic setting. Secondly, that the types of interaction and, therefore, the perceived benefit from collaboration is highly specific to the type of company (and their customers, need for skills, and knowledge).

Another more recent initiative in UK is the "Pathways to impact" launched by the Research Councils of UK (RCUK) which describes different domains of effects from research carried out at universities and technical colleges. One of these domains is "interaction with companies" and another domain describes effects in terms of shaping public policy and services [11] for example, benefits of research contributing to UK policies on how to change peoples' travelling behaviour. Statements regarding this type of broader description of usefulness of research is requested from researchers' activities in governmentally funded projects and although it may be difficult to foresee what the impact is (or may be) from planned research collaboration, it raises questions about knowledge transfer and perceived usefulness by private and public sector from collaborative projects with researchers based at universities. This example from the UK can, with a broader view of different categories of impacts, be important as a step towards incorporating different types of users' views of benefits from engaging in collaborative research. This issue of capturing impacts in evaluation of social sciences has received renewed attention [13] and can benefit from incorporating the collaborative effects and benefits as they are articulated by different user groups engaging in collaborative research.

The discussion about effects of collaborative research also raises questions about the value of including users of services or products early in the innovation process. Studies of innovation and invention networks describe this in terms of "userinnovation" or "open innovation" [2]. These concepts can also be used to describe user-interaction in the area of climate change policy [8] and roles of users in the innovation process [1], [9]. Other methods for engaging users in the innovation process are developed in the field of environmental futures studies, where citizens can have a say in describing what new services and ICT solutions they consider to be important to solve the environmental challenges of tomorrow for transport and mobility [10]. Actively incorporating experiences from ICT companies themselves is another way of integrating the user perspective on how private firms are perceiving environmental challenges and what solutions they can see on the horizon from a business point of view [6], [7] in the area of ICT and new media for sustainable solutions in a future society.

The expectations of ICT as a "key enabling technology" that can solve many problems in future society is not new. From a Swedish and European perspective there is however a renewed attention to this issue. This can be seen in the reply by the Swedish Agency for Innovation System (Vinnova) to the European Union's Green paper 
about European research and innovation ${ }^{1}$ where research is expected to respond to and solve several of the Europe's futures challenges. Among these Grand Societal Challenges are questions related to finding solutions to environmental problems by the increased use of ICT and other key enabling technologies to face challenges by industry [15]. These challenges are described in terms of finding energy efficient solutions, sustainable cities, and using the potential in the interaction achieved by partnerships between actors to enhance competitiveness.

One reason for studying innovation systems, from an environmental policy perspective, is to identify system weaknesses that require different kinds of policy interventions to balance the inertia for change and other barriers for new markets to evolve [5]. Some areas of policy interventions (that seek to reduce the system weaknesses) that are described aim to improve the framework conditions for development of new knowledge, create arenas for entrepreneurial experimentation, resources and incentives for actors in the innovation system develop new more environmentally efficient technology. This can, in turn, be an important part of the puzzle to facilitate the emergence of new markets for environmentally compatible technology solutions and to enhance the legitimacy for new sustainability-oriented innovations. For the innovation system as a whole, the knowledge that is generated in interaction between actors in certain domains of technology, in centres such as the CESC, can serve as a way to cater for the transfer of knowledge between actors in the system (between users, producers, universities, and firms etc.). In the case of the CESC, an operational and practical task is to explore the potential for interdisciplinary teams to understand processes of behavioural change in both citizens and firms (through ethnography, sociology, and business management), and how to integrate that knowledge with tools for environmental management in companies (Life Cycle Assessment, environmental strategies) with technical skills relating to ICT and new use of media technology in sustainable communication.

So in conclusion to the policy perspective on collaboration, this brief review indicates that research partnerships and collaborative projects in ICT carry expectations to solve some major challenges in industry and societal challenges relating to seeking more environmentally compatible ways of living, travelling and sustainable communication. The next question is how we can describe the dimensions of different types of benefit or "usefulness" that the different partners and consortiums see from examples of collaboration carried out by CESC?

The categories used for analysis of interaction benefitted from a framework developed in a study about measuring societal impacts from participatory sustainability research [12]. The categories are further described in the following section outlining the scope of the investigation carried out by CESC about different types of effects from collaborative research including university and companies in the ICT sector.

The literature study resulted in the conclusion that partner benefit can be classified into six categories:

\footnotetext{
${ }^{1}$ European Commission, From Challenges to Opportunities: Towards a Common Strategic Framework for EU Research and Innovation funding, Green Paper, COM(2011) 48.
} 
1. Increased knowledge and competence.

2. New contacts and network.

3. Increased credibility.

4. New products in the form of publications, methods and technology.

5. Processual and behavioural changes towards more sustainability.

6. Business value/Operational value.

These were not formulated as six distinctive categories when the interviews started, but came out of a combination of the development of the interviews and the literature.

\section{$4 \quad$ Results}

When partners describe in what ways the CESC collaboration has been of use to them, the aspect given most importance is the increased knowledge and competence within the area of sustainability and ICT that they have gained. The second most important outcome that partners consider is the credibility of the value added to their internal sustainability work when meeting clients, chief executive officers and coworkers, and also the extended network between partners, KTH and the companies, and within KTH internally. Scientific articles that result from the collaborative research are considered important mainly by the industrial CESC partners. Processual and behavioural/routine changes are harder to link to the partnership, while the internal sustainability work is considered as strengthened. It is seen as being too early to evaluate business value, but the partners all agree that they see a lot of potential for this in the future. Two corporate partners note that they have made cost savings due to decreased travelling partly as a consequence of focusing more on mediated meetings and highlighting the environmental effects of travel. Another aspect mentioned by partners is that research is more efficient when done in collaboration rather than on their own. Partners also maintain that the primary outcome of the collaboration is not seen necessarily as new products per se, but rather learning new methods, technology and getting new knowledge, which then can lead to learning loops within the partners' internal organization. Below some of the different categories mentioned above are described more in-depth.

\subsection{Increased Knowledge and Competence}

Increased knowledge and competence is a key result area emphasised by the partners when discussing the outcome of the CESC partnership. Some of the outcomes brought up and estimated by the partners are, for instance, learning a new way of doing things, working long-term and having the possibility to become immersed in a topic or research area and learn the process of publishing articles. Other important aspects related to increased knowledge are getting wider and deeper approaches to the concept of sustainability that also includes areas as behaviour and other social aspects. Getting more knowledge concerning environmental issues with related quantifiable measures is yet another important factor raised by the partners. It is seen as something positive 
to gain knowledge about how large the environmental impacts of their specific activities and specific products are.

One company explained the value of the broad range of competence of the centre and the analytic approach applied in the collaboration with the KTH-based centre CESC:

"The way of thinking at KTH/CESC is different - another time perspective. There is an analytical capacity and you get time to think and re-consider different aspects and not just accept a number. Our data is more credible when including different aspects (of the problem). It is also good that the project teams are not just including engineers - but also sociologists, psychologists, behavioural scientists - which is competence that we do not have at the company."

\subsection{New Contacts and Networks}

Partners find being part of the CESC network as a great value. To be able to exchange ideas and experiences, and have a platform for discussing complicated issues with people that have a variety of backgrounds, knowledge, experiences and motives, is treasured. The CESC partnership has also led to many new contacts between the different corporate partners. New contacts have also been established between researchers and companies and internally within KTH. The new networks have also resulted in several new collaborations that have been set up around common issues. For example, companies express that they have gained "a natural collaboration with other companies" and, from the university perspective, the collaboration with firms also provides new research questions that would not have been formulated otherwise.

One company expressed a value from new contacts and networks in terms of exchange of experiences and sharing knowledge:

"There is a great value in being able to network with collaboration partners, interesting partners, some of which are competitors."

A public sector partner involved in traffic and infrastructure plans in the Stockholm region explained:

"The collaboration creates discussion and a dialogue that helps us to find arguments or new questions that will be interesting to respond to in the future".

\subsection{Increased Credibility}

Collaborating with CESC gives the partners (both corporate and internal to KTH) increased credibility, an increased legitimacy within the area of sustainable ICT, a better position on the market and good public relations. Quality assured data gives an increased credibility and a better image to the companies' sustainability work both internally towards management and co-workers, and externally towards clients and suppliers. One concrete example of how this works is quantified environmental assessments and Life Cycle Assessments. When working with technological issues, it is a major credibility factor to be involved in collaboration with KTH. Credible research 
results give the corporate partners a position on the market. CESC has also helped to position KTH in the areas of ICT and sustainability. To KTH partners, and CESC itself, the collaboration with established and well-known corporate partners gives increased status and legitimacy. The partnership with CESC is often mentioned in annual reports and in relation to lectures, something that has great public relation's value. CESC's partners express that it is important to review their own organization (environmental impact, etc.) if they want to maintain their credibility.

Credibility is also mentioned in terms of CESC becoming a recognized competence centre internationally through collaboration with some leading institutions. According to a KTH researcher:

"CESC now has a position as one of the world's most interesting centres in the area ... as shown by collaboration with Waterloo in Canada and MediaLab at MIT”.

\subsection{New Products in the Form of Publications, Methods and Technology}

Several scientific articles, reports and dissertations have been produced as a result of the collaboration between CESC and the partners. The corporate partners have participated in the projects in all phases of the projects. The publications (i.e. reports, articles, and so on) are emphasized time and again in the interviews as one of the most important results of the collaboration. Another significant result is the development of a detailed Life Cycle Assessment, different methods for studying city climate goals, and how to measure quantitatively a climate neutral city.

Various partners point out that the aim of their CESC partnership lies beyond mere technological development. Instead they request a broader scope and an opportunity to grasp and understand the complex processes of ICT, media and sustainability and how this can be linked to behavioural changes, both ongoing and coming. Some partners state that it is too soon to show results yet, but they are looking forward to seeing what the results will be. One type of activity, also mentioned by partners is seminars arranged by CESC.

\subsection{Processual and Behavioural Changes towards More Sustainability}

It is quite difficult for partners to assess the extension of impact on internal processes (such as policies and routines) towards increased sustainability that is the outcome of the CESC collaboration, and to know what would have been gradual changes in a more sustainable direction anyway. It is, however, likely that the partnership has speeded up the process in the internal organization of some partners. KTH has certainly been influenced, particularly the division of environmental strategies research (fms). The central organization of KTH has also created several positions and added organizations in relation to increased sustainability.

Many project members state that they have experienced a personal growth as part of the collaboration, and it has been stressed that the work is meritorious on an individual level. The potential of cross-recruitment, i.e. recruiting of employees between 
partner organizations, is also something mentioned in the evaluation as well as implementation of ICT solutions in pilot projects.

"The collaboration with CESC has enabled us to start our digital conference system. There is a room and a pilot-project is launched. This has facilitated daily meetings between cities replacing daily travels within Sweden."

Other partners of CESC emphasize changing procurement of services where a travel agency was replaced to obtain feedback about environmental impact from travels and changes in travel patterns (favouring train options when possible) as a result of the travel policy.

\subsection{Business Value/Operational Value}

Several corporate partners think that there is potential business value in the collaboration with CESC because the clients are attracted by the fact that there is quantitative published data. Two corporate partners have noticed savings on travel, something that is related to impacts on company policy by the CESC collaboration.

However, some corporate partners say it is too soon to present commercial results, a fact referenced to short-term collaboration, but long-time corporate partners also state that it is too soon to see any economic results. The private sector partners also express the differences between their (daily) activities and the nature of the research process in relation to the expectations about "applicability" of research reports directly to their business activity, concluding that:

"The journey is more rewarding than the result, and maybe that is the way it has to be”.

Other private sector partners of CESC describe that the collaboration with CESC in projects has also opened up other types of networks as a result of interest from other firms relating to collaborative research with CESC.

\section{Conclusions}

Some conclusions can be drawn from the experiences of the CESC at KTH in Stockholm. These conclusions both relate to different types of benefits that can be discerned from collaborative projects involving CESC and also from some practical lessons from collaborative projects between university-based researchers, firms and partners from public sector.

Some practical lessons from the work at CESC and reviewing effects from collaborative projects are:

- It takes time to develop collaborative projects, so any evaluation of results or expected outcomes needs to take that into consideration.

- Involving people with decision power in the organization is of key importance. Making changes in organizations is not done easily - even if it is motivated by sustainability objectives. 
- The importance of tracking different dimensions of what are the expected benefits of collaboration rather than either a general "usefulness" or alternatively reliance on traditional indicators (patents, spin-offs) that may not capture the different domains of benefits that comes out from collaborative projects that involves such a diverse set of public-private actors.

Experiences from CESC about the benefits from the viewpoint of the private sector partners reveal a number of different effects that the collaborative projects generated:

- The collaboration with CESC also catalysed contacts with other firms.

- Access to a broad range of knowledge domains relevant to understand travel behaviour.

- An analytical 'mind set' about environmental impact of the firm.

- New routines for the firm's own travel plans to reduce environmental impact

These points indicate some benefits at the firm-level arising from collaborative projects, as described by the companies themselves, in terms of processes of change within the firm that are necessary for credibility towards customers and markets. In a wider policy context these results reflect some aspects of business value in sustainability as well as respond to grand societal challenges described by the European Union and at national level. This wider policy discussion about the potential of key enabling technologies, such as ICT, emphasizes the importance of involving users in the quest for sustainable and environmentally responsible innovation. The examples and experiences shown here from CESC offer a small step towards operationalizing these grand words into practices that can provide some guidance on how to describe, in a meaningful way, different types of effects from collaborative projects about environmental sustainability.

The broad range of different types of effects raised by the private CESC partners relates to the theme of partner benefit that is defined in the general goals for CESC; to be a resource when it comes to ICT and sustainability; that CESC activities lead to a continuous growth in importance when it comes to positive sustainability effects; and that CESC partners find the activities within CESC beneficial for long-term business. Other goals stated by CESC relate to societal impact and can be mirrored in the responses regarding, for example, visibility of CESC nationally and internationally (visible through collaboration with leading institutions). The use of results from CESC leads to sustainable practices in society. Examples of the latter are found both by responses by public sector partners (identifying new questions in travel and infrastructure planning) and private firms (procedural changes and individual travel choices) with benefits for sustainable communications.

There are some broader lessons from this case that can be valuable for other centres engaged in collaborative research and development that targets sustainable communications or planning when setting up collaborative projects aiming for integrating environmental sustainability with innovation. To catalyse some of the benefits from new networks (with universities, but also with firms and public sector partners) that 
we have discussed here, the centres can benefit from introducing regular seminar activities in addition to specific project collaboration in teams. This creates forums for interaction that facilitate spontaneous interaction and sharing the "odd idea" that may be an inspiration to a joint initiative in the future. Public-private collaboration involving university-based Centres of Excellence is targeting collaborative projects, but is also ultimately about meetings between people so that seminars can be an important arena for exploring areas of shared interest.

Another lesson is to encourage collaboration partners to express their expectations in greater detail rather than in general terms about "being useful" to the company. This will help the centre to identify and define process values in partner organizations and see where the centre can play a role - whether it is to reduce environmental impact, create pilots for ICT solutions; understand processes of behavioural change for travels; and how to make these aspects visible to the organization as a whole.

\section{References}

1. Bienkowska, D., Larsen, K., Sörlin, S.: Public-private innovation: Mediating roles and ICT niches of industrial research institutes. Innovation: Management Policy and Practice 12, 206-216 (2010)

2. Chesbrough, H.: Open Innovation: A New Paradigm for Understanding Industrial Innovation. In: Chesbrough, H., Vanhaverbeke, W., West, J. (eds.) Open Innovation: Researching a New Paradigm, pp. 1-12. Oxford University Press, Oxford (2006)

3. Faulkner, W., Senker, J.: Making sense of diversity: public-private sector research linkage in three technologies. Research Policy 23, 673-695 (1994)

4. Jacobsson, S.: Universities and industrial transformation: an interpretative and selective literature study with special emphasis on Sweden. Science and Public Policy 29(5), 345-365 (2002)

5. Jacobsson, S., Bergek, A.: Innovation system analysis and sustainability transitions. Environmental Innovation and Societal Transitions 1, 41-57 (2011)

6. Kramers, A., Gustafsson, G.M.: How telecom could save the planet. Ericsson Business Review 1, 17-21 (2009)

7. Larsen, K.: Science and technology parks and the integration of environmental policy. Innovation, Management, Policy and Practice 6(2), 294-305 (2004)

8. Larsen, K., Gunnarsson-Östling, U., Westholm, E.: Environmental scenarios and localglobal level of community engagement - environmental justice, jams, institutions and innovation. Futures 43(4), 413-423 (2011)

9. Larsen, K., Gunnarsson-Östling, U.: Climate change scenarios and citizen-participation: Mitigation and adaptation perspectives in constructing sustainable futures, Habitat International. Special Issue on Climate Change and Human Settlements 33(3), 260-266 (2009)

10. Larsen, K., Höjer, M.: Technological innovation and transformation perspectives in environmental futures studies for transport and mobility. International Journal of Foresight and Innovation Policy (IJFIP) 3(1), 95-115 (2004)

11. RCUK Research Councils UK, Pathways to impacts (2011), http: / / www.rcuk.ac.uk/kei/impacts/Pages/home.aspx 
12. Robinson, J.: Report from project: Measuring societal impacts from participatory sustainability research. Social Sciences and Humanities Research Council of Canada (2008)

13. SSHRC: What have we learned about 'capturing impacts' in Social Sciences and Humanities? Report by the Social Sciences and Humanities Research Council (2010)

14. Vinnova: Guidelines for the Second evaluation of VINN Excellence Centres, Stockholm (2011)

15. Vinnova: Vinnova position paper on the common strategic framework, Stockholm, May 5 (2011) 